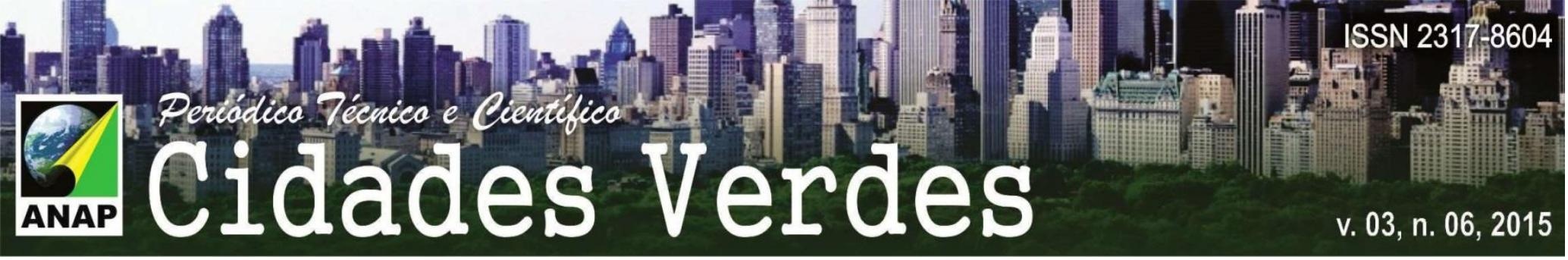

\title{
ZONEAMENTO AMBIENTAL URBANO EM JAGUARÃO - RS
}

\author{
Luana Pavan Detoni ${ }^{1}$
}

Maurício Couto Polidori ${ }^{2}$

Otávio Martins Peres ${ }^{3}$

\section{RESUMO}

O Zoneamento Ambiental Urbano consiste numa etapa fundamental do planejamento urbano contemporâneo, baseado na cidade enquanto fenômeno complexo, e tem como objetivo articular o desenvolvimento das cidades, incluindo a sociedade, os elementos construídos e a dimensão ambiental nas suas múltiplas dimensões e variáveis. Elaborado a partir de um projeto que integra as ações de pesquisa, ensino e extensão do Laboratório de Urbanismo da Faculdade de Arquitetura e Urbanismo da Universidade Federal de Pelotas e das experiências e técnicas da Secretaria de Planejamento e Urbanismo da Prefeitura Municipal de Jaguarão, o Zoneamento Ambiental Urbano da Cidade de Jaguarão, localizada na fronteira entre o Rio Grande do Sul - Brasil e o Uruguai, buscou diferenciar a paisagem de suporte à urbanização, identificar às áreas indicadas à preservação dos recursos naturais e incluir as variáveis ambientais como protagonistas no jogo de inter-relações e interesses sobre o ambiente urbano. Esse processo envolveu coleta, organização e análise das informações existentes, em conjunto com a interpretação da legislação e o reconhecimento dos valores ambientais junto a comunidade, e a partir desses resultados estabeleceu diretrizes com diferentes níveis de urbanização e preservação, a fim de e garantir a manutenção de atributos de interesse e valor ambiental e um planejamento coerente com a cidade e seu bioma natural, o pampa, assegurando a qualidade ambiental intraurbana do futuro.

PALAVRAS-CHAVE: Zoneamento Ambiental Urbano. Ambiente natural. Planejamento Urbano.

\footnotetext{
${ }^{1}$ Universidade Federal de Pelotas. E-mail luanadetoni@gmail.com

2 Universidade Federal de Pelotas. E-mail mauricio.polidori@gmail.com

${ }^{3}$ Universidade Federal de Pelotas. E-mail otmperes@gmail.com
} 


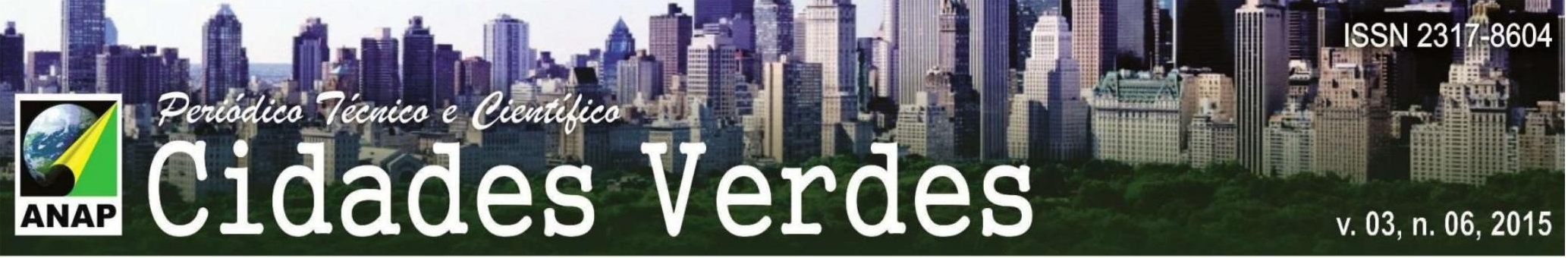

\section{RECONHECIMENTO DO VALOR AMBIENTAL}

A cidade de Jaguarão, com aproximadamente 28 mil habitantes (IBGE, 2010), está localizada na fronteira entre o Rio Grande do Sul - Brasil e o Uruguai e tem como cidade gêmea Rio Branco. Nesse contexto geográfico típico de zonas de fronteiras e dos seus respectivos processos de conurbação transnacionais é possível observar que a ocupação do território de Jaguarão historicamente teve forte relação com seu ambiente natural. Segundo Martins (2001), os acidentes geográficos exerceram influência no direcionamento da expansão do núcleo, principalmente o Rio Jaguarão e os dois riachos que nele desembocavam e os dois cerros no setor nordeste foram por muito tempo limites urbanos.

Figura 1: Mapa Aspectos Geográficos

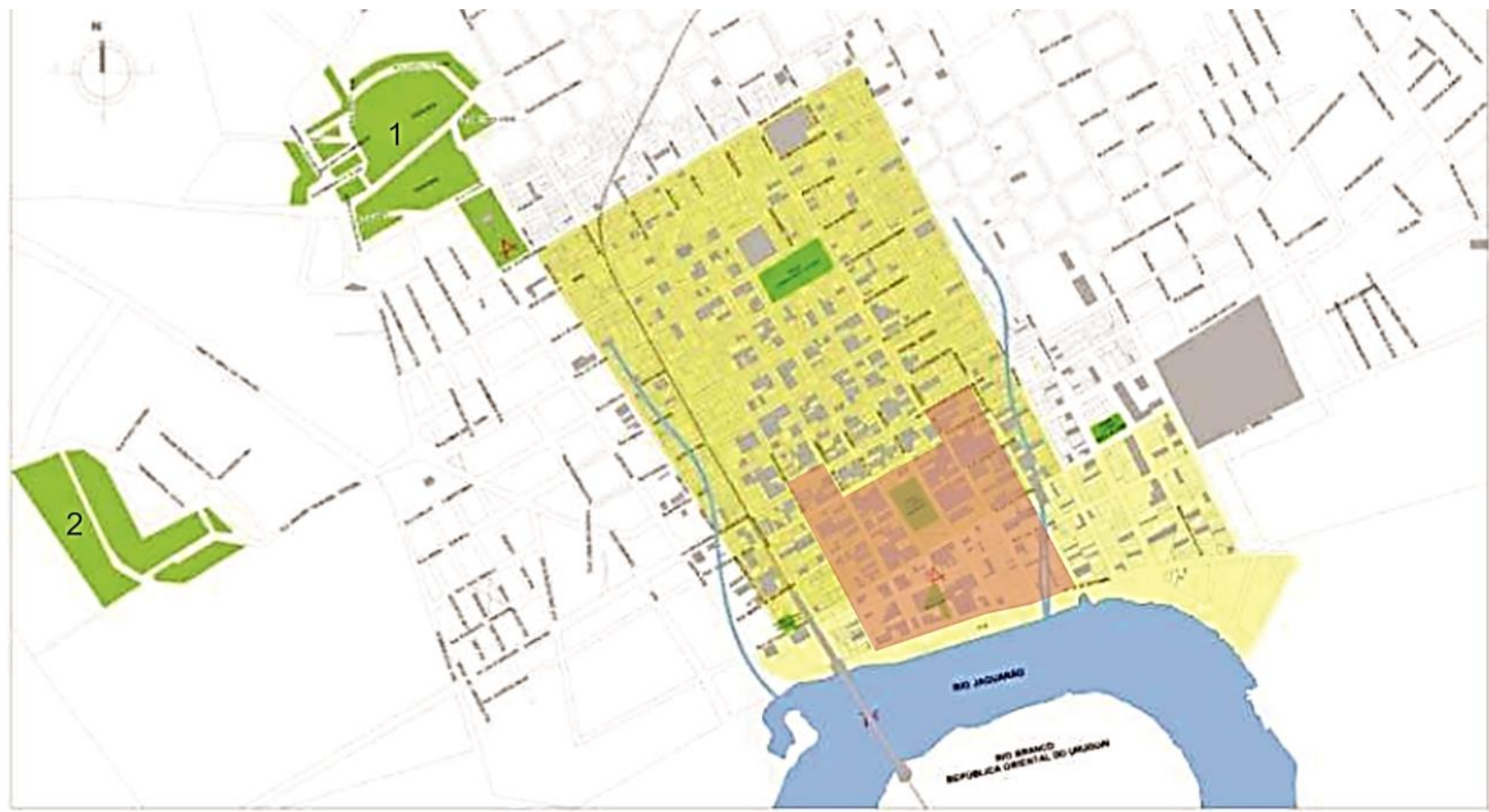

\begin{tabular}{|c|c|}
\hline 1 & Área elevada Cerro da Pólvora \\
\hline 2 & Área elevada Cerro das Irmandades \\
\hline
\end{tabular}

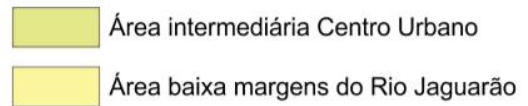

Área do loteamento traçado em 1815 Rio Jaguarão e antigos riachos

Fonte: Dossiê Tombamento Jaguarão - RS, editado pela autora, 2009. 


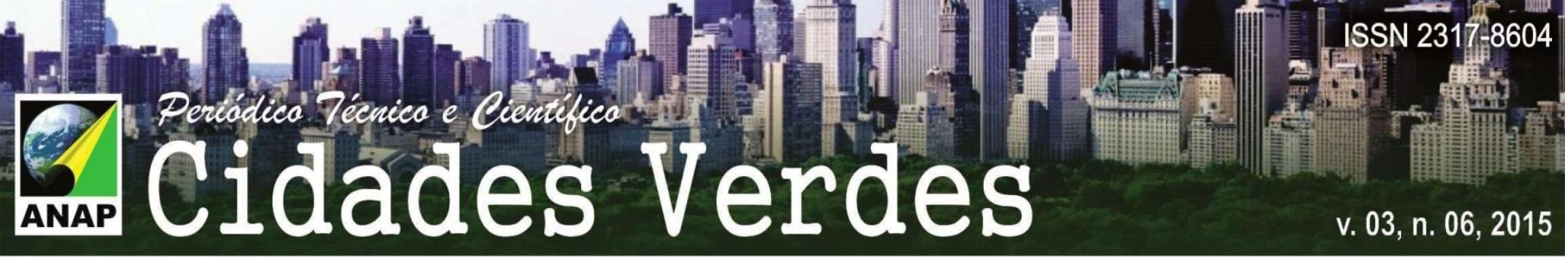

O Rio Jaguarão, juntamente com os dois riachos, o Cerro da Pólvora e o Cerro das Irmandades, aos quais o autor se refere, figura 1, receberam os primeiros equipamentos da implantação da cidade. A antiga guarda militar, inicialmente instalada no Cerro da Pólvora, cota mais elevada permitindo uma ampla visualização do território. A instalação do porto, na margem do Rio Jaguarão. E o traçado do primeiro loteamento, em 1815, sobre a área de altitude intermediária entre os dois riachos. (DOSSIÊ, 2009)

Assim como, na compreensão da influência da estrutura da paisagem na evolução urbana da cidade, o estudo do ambiente natural também teve como base a coleta, sistematização e análise das informações em ambiente de SIG, fundamentado no mapeamento da cobertura do solo, da topografia e da hidrografia. 


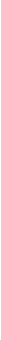

Figura 2: Mosaico Ambiental e Hidrografia, Jaguarão - RS

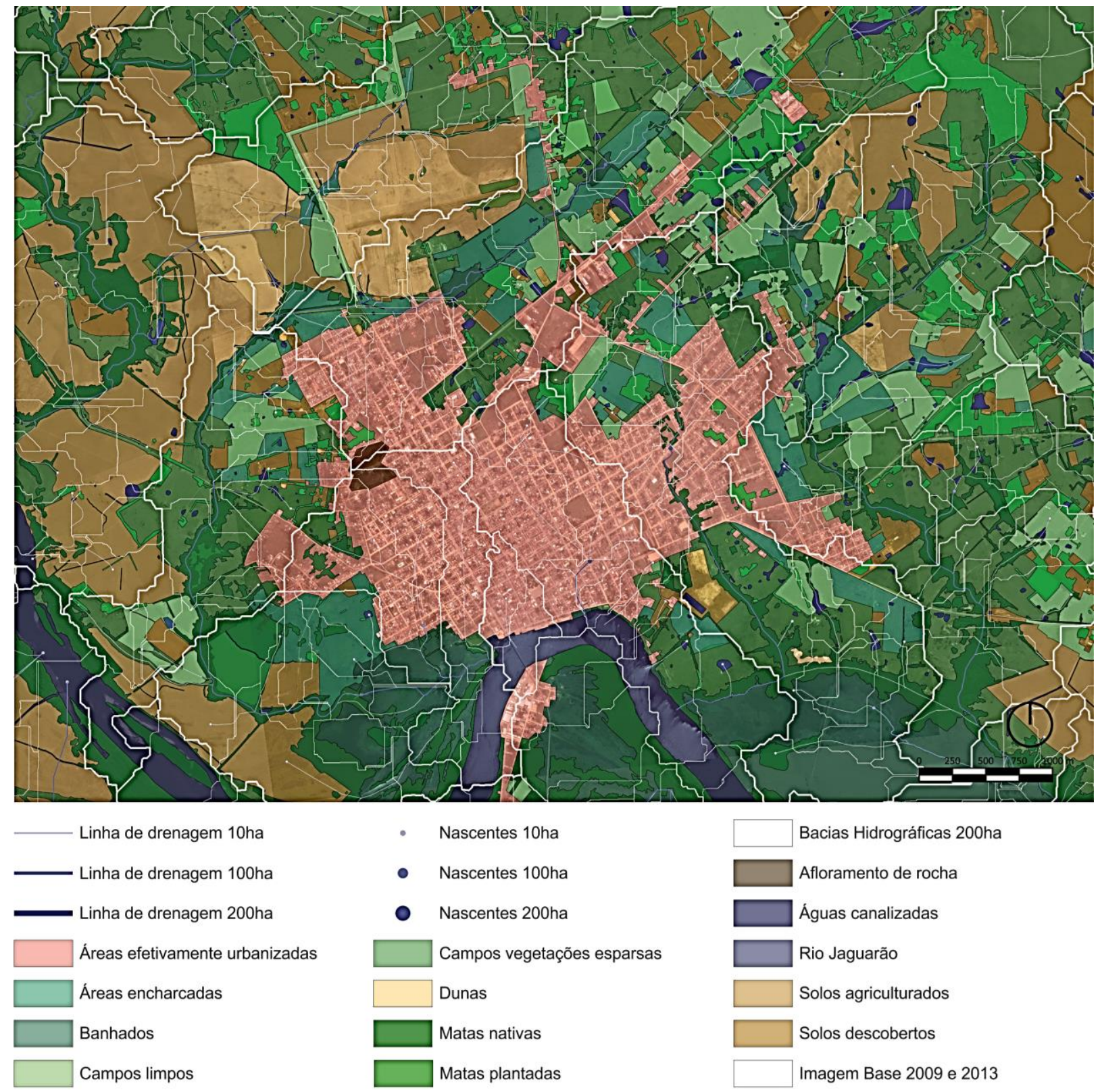

Fonte: Autora, 2015.

O mapeamento da cobertura do solo apropriou-se da técnica do mosaico, arte milenar cujo desenho tem o objetivo de preencher um plano através do encaixe de pequenas peças - tesselas. Essa técnica, que vem se diversificando ao longo dos tempos quanto aos seus materiais e aplicações, neste trabalho compõem o Mosaico Ambiental da cidade de Jaguarão, retomando a ideia do fragmento esse desenho 


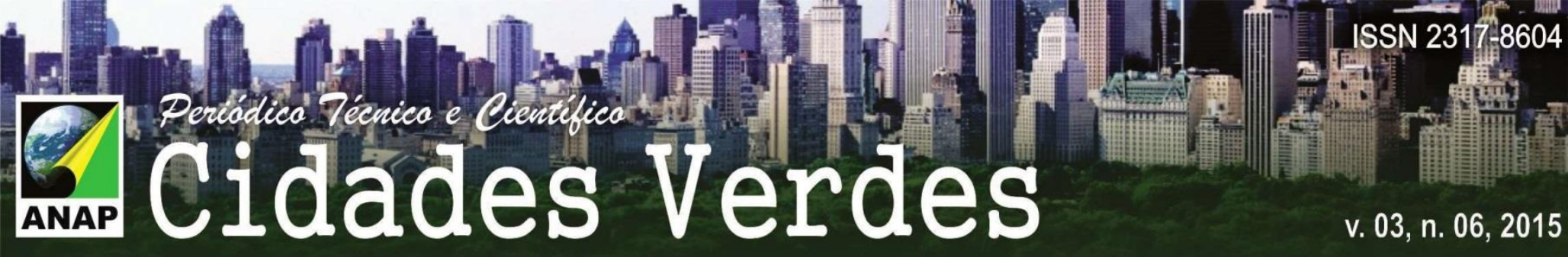

representa a partir da interpretação das imagens aéreas, de 2013 e complementar 2009, as relações estabelecidas entre o ambiente urbano e o ambiente natural.

De acordo com as definições de Santos (2004), mosaico refere-se à soma de imagens, mapas, fotos de áreas contíguas, de forma tal que representem uma superfície contínua. Uma paisagem que apresenta uma estrutura contendo mancha, corredores e matriz. As tesselas do Mosaico Ambiental da cidade de Jaguarão, figura 2, são formadas por quatorze componentes que configuram o ambiente estudado, identificados como: áreas efetivamente urbanizadas, solos agriculturados, solos descobertos, afloramento de rocha, dunas, Rio Jaguarão, águas canalizadas, águas lênticas, áreas encharcadas, banhados, campos limpos, campos vegetações esparsas, matas nativas e matas plantadas.

As áreas efetivamente urbanizadas compreendem as áreas com ocupação urbana consolidada. O produto é um desenho bastante recortado que corresponde mais com as expectativas de fragmento do Mosaico Ambiental e da formação inacabada da cidade, do que pelo perímetro urbano definido pelo Plano Diretor. As áreas efetivamente urbanizadas, juntamente com os solos agriculturados e os solos descobertos, representam as áreas antropizadas. Sendo perceptível nesses últimos, a degradação e a descaracterização das paisagens naturais do Pampa, geralmente frutos da progressiva introdução e expansão das monoculturas e pastagens, em especial das plantações de arroz.

O afloramento de rocha, exposição da rocha na superfície da terra, localizado no Cerro da Pólvora, no interior do perímetro urbano de Jaguarão representa uma área especial tanto geograficamente quanto culturalmente para a cidade. Nas imediações do Rio Jaguarão próxima dos banhados à sudeste, foi identificado a presença de dunas, essa formação característica do solo sedimentar denota, assim como o componente afloramento de rocha, as duas formações geológicas distintas da cidade. Os solos rochosos provenientes do escudo cristalino, presentes na porção à noroeste e os solos sedimentares provenientes da planície costeira, presentes na porção à sudeste.

O Rio Jaguarão, que delimita a fronteira entre as cidades gêmeas Jaguarão Brasil e Rio Branco - Uruguai, parte da Bacia de mesmo nome, localizada na Região 


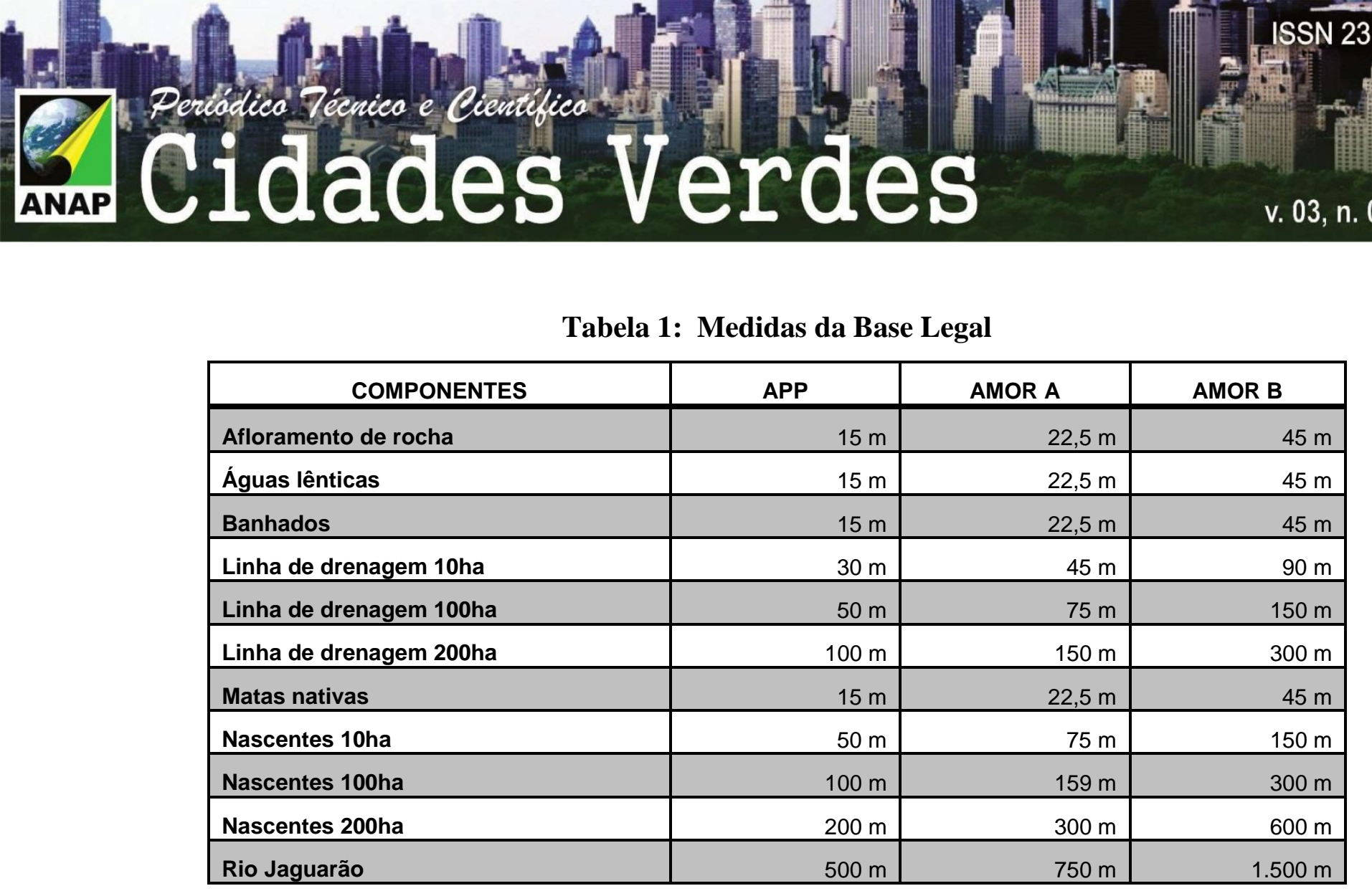

Fonte: Autora, 2015.

De acordo com a Base Legal foram elaboradas duas alternativas de Zoneamento Ambiental Urbano, figura 3 e 4, uma mais branda e outra mais rigorosa quanto as questões ambientais. Tendo como objetivo a avaliação das propostas junto à comunidade, através de oficina participativa, e consequentemente com o somatório dos resultados desse processo a consolidação e implementação do Zoneamento. As duas propostas, partem da mesma base e adotam as diretrizes de Preservar, Compensar, Renaturalizar, Mitigar e Urbanizar, diferenciando estas quanto ao grau de intensidade e aplicação.

A Proposta 01, figura 3, adotou medidas de acordo com os mínimos legais de proteção ambiental, prevendo que a cidade de Jaguarão possa reconhecer e consolidar suas áreas de preservação. Enquanto, a Proposta 02 , figura 4, adotou medidas mais exigentes quanto a preservação ambiental, prevendo uma cidade com maior potencial do ambiente natural. As duas propostas tem como premissa a preservação de todas as APP, ou seja proteger todas as áreas naturais existentes. $E$ como medidas de reparo as APP que estão modificadas adotar as ações de renaturalizar, mitigar e compensar.

A renaturalização, tange as APP que estão antropizadas por atividades agropecuárias, observável através dos componentes solos agriculturados e 


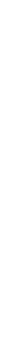

\section{CONCLUSÕES}

O planejamento urbano tem como finalidade atingir metas que num determinado tempo levem à melhoria dos ambientes urbanos e promovendo mais equidade física, social e ambiental. A experiência do Zoneamento Ambiental Urbano de Jaguarão, foi um processo contínuo que envolveu coleta, organização e análise das informações, por meio de procedimentos e métodos do geoprocessamento, da interpretação da legislação e do reconhecimento dos valores ambientais junto à comunidade para a tomada de decisões acerca das alternativas propostas. Contudo as diretrizes adotadas visam o melhor aproveitamento dos recursos naturais e urbanos disponíveis e a sustentabilidade das suas inter-relações.

\section{REFERENCIAS BIBLIOGRÁFICAS}

BRASIL. Áreas de Preservação Permanente de reservatórios artificiais e o regime de uso do entorno. Resolução $n^{\circ}$ 302, de 20 de março de 2002. Disponível em: http://www.mma.gov.br/. Acesso: maio, 2015.

BRASIL. Código Estadual do Meio Ambiente do Estado do Rio Grande do Sul. Lei $n^{\circ}$ 12.995, de 24 de julho de 2008. Disponível em: http://www.oabrs.org.br/. Acesso: maio, 2015.

BRASIL. Sistema Nacional de Unidades de Conservação. Lei n 9.985. Disponível em: http://www.mma.gov.br/. Acesso: maio, 2015.

BRASIL. Novo Código Florestal. Lei n` 12.651, de 25 de maio de 2002. Disponível em: http://www.planalto.gov.br/. Acesso: maio, 2015.

BRASIL. Política nacional de Proteção e Defesa Civil. Lei n 12.608, de 10 de abril de 2012. Disponível em: http://www.integracao.gov.br/. Acesso: maio, 2015.

BRASIL. Vegetação em Área de Preservação Permanente. Resolução $n^{\circ} 369$, de 28 de março de 2006. Disponível em: http://www.mma.gov.br/. Acesso: maio, 2015.

IBGE. Cidades. Disponível em: http://cidades.ibge.gov.br/xtras/perfil.php?codmun=431100. Acesso: maio, 2015.

FINGER, Anna. $O$ avanço da fronteira meridional. Conjunto histórico e paisagístico de Jaguarão-RS. Dossiê de Tombamento. IPHAN. 2009

MARTINS, Roberto Duarte. A ocupação do espaço na fronteira BrasilUruguay: a construção da cidade de Jaguarão. Tese. (Doutorado em Histórias Especializadas). Escola Técnica Superior de Arquitetura. Universidade Politécnica da Catalunha. 2001

MMA. Pampa. Disponível em: http://www.mma.gov.br/biomas/pampa. Acesso: maio, 2015.

SEMA. Bacias Hidrográficas do Rio Grande do Sul. Disponível em: http://www.sema.rs.gov.br/. Acesso: maio, 2015.

SCHUTZER, José Guilherme. Cidade e meio ambiente: A apropriação do relevo no desenho ambiental urbano. São Paulo: Edusp, 2012. 